\title{
全身麻酔は高齢者虚血性脳血管障害既往の脳に影響するか
}

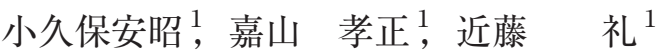 \\ 黄木 正登, 高岡 誠司 ${ }^{2}$
}

\section{The Influence of General Anesthesia on the Brain in Aged Patients with Previous Ischemic Cerebrovascular Disease}

\author{
Yasuaki KoKubo, M.D., ${ }^{1}$ Takamasa Kayama, M.D., ${ }^{1}$ Rei Kondo, M.D., ${ }^{1}$ \\ Masato OkI, M.D., ${ }^{1}$ and Seiji TAKAOKA, M.D. ${ }^{2}$ \\ Departments of ${ }^{1}$ Neurosurgery and ${ }^{2}$ Anesthesiology, Yamagata University Faculty of Medicine, \\ Yamagata, Japan
}

Summary: Whenever we discuss the overall results of surgical treatment for unruptured cerebral aneurysms, especially in aged patients, we tend to consider advanced age or general anesthesia as causes for unfavorable results. There are no reports concerning ischemic stroke events following general anesthesia in aged patients with a prior history of cerebrovascular disease. The purpose of this study is to clarify the influence of general anesthesia on the brain in aged patients with a previous history of ischemic cerebrovascular disease. The subjects were 30 consecutive patients over 70 years of age with previous ischemic cerebrovascular disease who underwent various surgeries except brain and cardiac surgery under general anesthesia. The patients were 70 to 85 years old, with a mean age of 76 . Twenty-three were men and 7 were women. Surgical procedures were 12 gastrointestinal, 6 orthopedic and 4 urogenital and others.

The type of cerebrovascular disease evaluated by neuroradiologist and anesthesiologist based on MR imaging was devided as follows: 16 patients had minor stroke, 7 had TIA/RIND and 7 had asymptomatic cerebral infarction. MR angiography was also assessed to evaluate the main artery in the brain. Blood pressure and arterial blood gas $\left(\mathrm{PaCO}_{2}\right)$ during general anesthesia were analyzed, and the rate of systemic and neurological complications following general anesthesia were evaluated. MR angiography revealed no occlusion or severe stenosis of the main artery in the brain of any of the patients. The minimum systolic blood pressure showed less than $100 \mathrm{mmHg}$ transiently for 5-20 minutes in 28 of 30 patients during general anesthesia. The minimum value was $65 \mathrm{mmHg}$ maintained for 5 minutes. The minimum $\mathrm{PaCO}_{2}$ during general anesthesia was as follows: 1 case $<25$ mmHg, 7 cases $26-30 \mathrm{mmHg}, 10$ cases $31-35 \mathrm{mmHg}, 9$ cases $>36 \mathrm{mmHg}$. There were no neurological complications following general anesthesia in this study. One of 30 patients (3.3\%) had suffered from pneumonia following total gastrectomy.

Except for various surgeries performed under general anesthesia with long-lasting hypotension and hypocapnia, general anesthesia has no effect on the brain in aged patients with previous ischemic cerebrovascular disease without occlusion or severe stenosis of the main artery in the brain.
Key words:

- influence on brain

- general anesthesia

- aged patient

- previous ischemic cerebrovascular disease

- blood pressure

Surg Cereb Stroke (Jpn) 36: 125-128, 2008

${ }^{1}$ 山形大学医学部 脳神経外科, ${ }^{2}$ 同 麻酔科 (受稿日 2007.9.4) (脱稿日 2007.10.17) 〔連絡先： † 990-9585 山形市飯田西 2-2-2 山形大 学医学部 脳神経外科 嘉山孝正] [Address correspondence: Takamasa KAYAMA, M.D., Department of Neurosurgery, Yamagata University Faculty of Medicine, 2-2-2 Iidanishi, Yamagata 990-9585, Japan] 


\section{はじめに}

脳神経外科医が手術成績を議論する際に, 悪い結果の要 因として全身麻酔の影響をあげることがある7 . 特に高齢 者で虚血性脳血管障害の既往がある患者で, 術後の脳梗塞 が生じた場合に手術そのものによる合併症ではなく, 全身 麻酔をその誘因のひとつとしていることがある ${ }^{216-8)}$ 。す なわち全身麻酔をすることで, 術後虚血性脳血管障害合併 症が発生する危険因子としては, 脳血管障害の既往, 高血 圧, 心房細動, 高齢, 動脈硬化が報告されている5). minor completed stroke 以上の重症症状が残存する脳卒中 既往のある全身麻酔下手術例においては連続 173 例中 5 例 (2.9\%) に周術期虚血性脳血管障害が発症したと報告されて いる3). しかし, 軽症の無症候性やラクナ梗塞などの軽症 脳卒中既往がある高齢者の症例を対象とし, 全身麻酔を施 行した際の脳に与える影響を検討した報告はない.今後は 高齢者で軽症の虚血性脳血管障害の既往がある患者に対す る外科的治療は増加していくと考えられ, 手術適応の決定 や周術期管理において外科手術における全身麻酔の影響を 明らかにしておく必要がある.

そこで，今回われわれは軽症の虚血性脳血管障害既往の ある高齢者における全身麻酔のみの影響を検討するため, 70 歳以上の高齢者における脳神経外科, 心臟外科手術を

Table 1 Surgical procedures performed

\begin{tabular}{lc}
\hline Procedures & $n$ \\
\hline major abdominal & 12 \\
orthopedic & 6 \\
urologenital & 4 \\
non-cardiac thoratic & 3 \\
otorhinolaryngological & 3 \\
mastectomy & 1 \\
ophthalmological & 1 \\
\hline
\end{tabular}

Table 2 Type of previous cerebrovascular disease and risk factors

\begin{tabular}{ll}
\hline & Patients, $\mathrm{n}(\%)$ \\
\hline Type of previous stroke & \\
minior completed stroke & $16(53.4)$ \\
TIA/RIND & $7(23.3)$ \\
asymptomatic & $7(23.3)$ \\
\hline Risk factors & \\
hypertension & $20(66.7)$ \\
diabetes & $2(6.7)$ \\
ischemic heart disease & $5(16.7)$ \\
\hline
\end{tabular}

除く全身麻酔下手術の周術期虚血性脳血管障害合併症につ いて検討を行った。

\section{対象}

最近 3 年間に当院にて脳神経外科, 心臓外科手術を除く, 脳塞栓症を起こさない手術で虚血性脳血管障害既往のある 70 歳以上の全身麻酔施行例 30 例を対象とした。年齢は 70-85歳 (平均 $76 \pm 3.8$ 歳), 男性 23 例, 女性 7 例であった。

\section{方法}

\section{(1)対 象}

既往に虚血性脳血管障害がある症例の選択は神経放射線 科および麻酔科に依頼した。脳神経外科以外の全身麻酔患 者を神経放射線科と麻酔科にて，亿）入院時，虚血性脳血 管障害による症状がない症例のうち，1） MRI (T1, T2, DWI，FLAIR）画像上所見がなくとも明らかな TIA（transient ischemic attack), RIND (reversible ischemic neurological deficit)の既往のある症例，2）既往に TIA, RINDがなくともMRI 画像上，虚血性脳血管障害の所見 のある症例 (無症候性脳梗塞症例), 3) 既往に TIA, RIND があり, MRI 画像上虚血性脳血管障害の所見のある 症例と, 口) 入院時, 虚血性脳血管障害による症状が残存 している completed strokeの症例として，以上のイ）ロ) に適合する症例を連続 30 例選択した。

(2)分析方法

麻酔中の血圧, $\mathrm{PaCO}_{2}$ および $\mathrm{MRA}$ の所見, 術後の全身 合併症と脳血管障害発生率を症状および MRI 画像にて検 討した.

\section{結果}

\section{(1)手術内容}

Table 1 に施行した手術内容を示す. 12 例で腹部外科手 術, 6 例で整形外科手術, 4 例で泌尿器科手術, 3 例で呼 吸器外科手術, 3 例で耳鼻咽喉科手術, 1 例で乳房切除術, 1 例で眼科内腫瘍摘出術であった。

(2)既往の虚血性脳血管障害

16 例 (53.4\%) が minor completed stroke, 7例 (23.3\%)が TIA/RIND, 7 例 (23.3\%) が無症候性脳梗塞であった。 MRI上は, 主にラクナ梗塞や比較的小さい皮質枝領域の 脳梗塞を認めた。また，30 例中 20 例 (66.7\%) に高血圧症 の既往を認め， 2 例 (6.7\%) で糖尿病，5例 (16.7\%) で虚血性 心疾患を認めた (Table 2).

(3) MRA 所見

全 30 例中 MRA 上, anterior circulation および posterior circulationに脳主幹動脈の閉塞, 高度狭窄病変を認め た症例はなかった。 


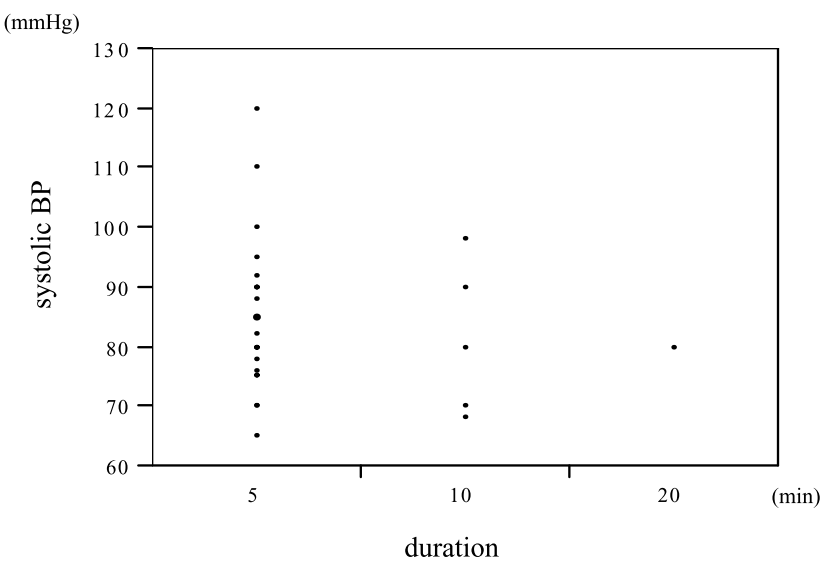

Fig. 1 Minimum systolic blood pressure (BP) and the duration during general anesthesia.

The minimum systolic blood pressure showed less than $100 \mathrm{mmHg}$ transiently for $5-20$ minutes in 28 of 30 patients during general anesthesia. Minimum value was $65 \mathrm{mmHg}$ maintained for 5 minutes.

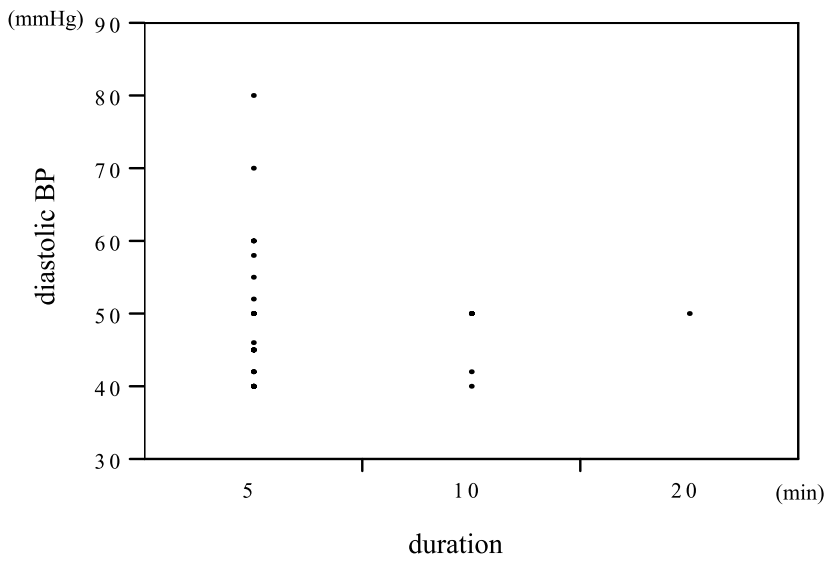

Fig. 2 Minimum diastolic blood pressure (BP) and the duration during general anesthesia.

The minimum diastolic blood pressure was $40 \mathrm{mmHg}$ maintained for 5 minutes.

\section{(4)麻酔所見結果}

11 例にプロポフォール，9例にイソフルレン，10例に セボフルレンを使用した。麻酔時間は平均 $259 \pm 122$ 分 (80-560 分)であった。

(5)麻酔中の血圧および $\mathrm{PaCO}_{2}$

全身麻酔中の収縮期および拡張期の血圧を Fig. 1 と Fig. 2 に示した。 30 例中 28 例で最低収縮期血圧が一過性に 100 $\mathrm{mmHg}$ 以下となり, その持続時間は5-20 分 (平均 6 分 20 秒士 3 分 12 秒) であった。収縮期血圧の最低值は $65 \mathrm{mmHg}$ で持続時間は 5 分であった。拡張期血圧の最低值は 40 $\mathrm{mmHg}$ で持続時間は 5 分であった。

Fig. 3 に全身麻酔中の $\mathrm{PaCO}_{2}$ を示した. $25 \mathrm{mmHg}$ 以下 を呈したのは 1 例，26-30 mmHg を呈したのは 7 例，

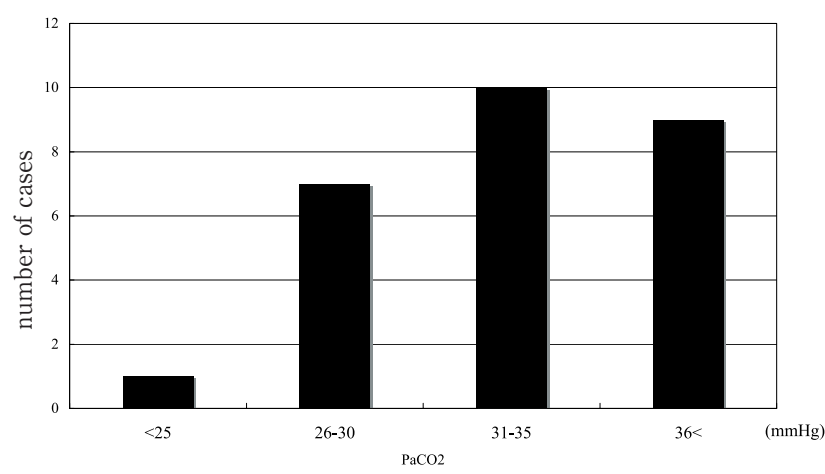

Fig. 3 Minimum $\mathrm{PaCO}_{2}$ during general anesthesia. Minimum $\mathrm{PaCO}_{2}$ during general anesthesia was as follows: 1 case $<25 \mathrm{mmHg}$, 7 cases $26-30 \mathrm{mmHg}$, 10 cases 31-35 mmHg, 9 cases $>36 \mathrm{mmHg}$.

Table 3 Overall results

\begin{tabular}{ll}
\hline & $\mathrm{n}(\%)$ \\
\hline Systemic complication & $1 / 30(3.3 \%)$ \\
Neurological complication & $0 / 30(0 \%)$ \\
\hline
\end{tabular}

31-35 mmHg を呈したのは 10 例， $36 \mathrm{mmHg}$ 以上を呈した のは1例であった.

(6)術後の全身合併症と脳血管障害発生率

Table 3 に結果を示した． 30 例中，神経学的合併症は呈 した症例はなかった。また, 術後 5 日目から 2 力月の退院 後に MRIの評価を行い，新たな無症候性脳梗塞の出現は 認めなかった．脳卒中以外の術後合併症は胃全摘手術後の 1例 (3.3\%)で術後肺炎を認めたのみであった。したがって, 今回の検討では 70 歳以上の高齢者で虚血性脳血管障害の 既往がある症例では，全身麻酔下手術において周術期虚血 性脳血管障害を呈した症例はなかった。

\section{考察}

脳神経外科領域において特に未破裂脳動脈瘤の手術を考 慮する場合，単に高龄者で虚血性脳血管障害の既往がある という理由だけで，手術を施行しなかったり，手術を施行 しても神経学的合併症が生じた場合に手術によるものでな く, 虚血性脳血管障害の既往と全身麻酔を原因とする論文 が認められる2(6)9). 一方で，これまで高齢者において虚 血性脳血管障害の既往と全身麻酔の脳への影響のみを評価 した報告はない。

今回の検討では 70 歳以上の高齢者で軽症の虚血性脳血 管障害の既往がある脳神経外科，心臓外科手術を除く，脳 塞栓症の起きない手術症例に対し全身麻酔下手術を施行 
し，30例中 1 例 (3.3\%) で胃全摘手術後に肺炎を合併した が，神経学的合併症を呈した症例はなかった。

術中血圧については結果で示したように最低収縮期血圧 が 5 分以内ではあるが $65 \mathrm{mmHg}$ となった症例が 1 例あっ たのみで長時間の低血圧を呈した症例はなかった。 Landercasper らの報告 ${ }^{3)}$ では脳卒中既往のある全身麻酔 下手術例において連続 173 例中，5例 (2.9\%) に周術期虚血 性脳血管障害が発症したと報告されている。 Landercasper らの対象症例では脳塞栓症が 30 例 (17.3\%), 脳血栓症が 28 例 (16.2\%), 出血性脳血管障害が 22 例 (12.7\%), 病型は不明だが周術期脳卒中既往例が 4 例, 不 明およびその他が 89 例であり, このうち 2 回以上の脳卒 中既往のある患者は 42 例 (26.6\%) であった。また，後遺症 については 153 例 (88.4\%)に運動麻疩, 80 例 (46.2\%) に言 語障害，脳神経障害 35 例 (20.2\%)，知覚障害 20 例 (11.6\%) が残存していた。したがって本研究と比べ症例数は多いも のの重症の症例であり，われわれの検討した軽症例での既 往脳卒中患者のみを対象としていない. また, 術後回復室 での収縮期血圧 $90 \mathrm{mmHg}$ 以下に関連していたとしている が，持続時間および脳主幹動脈の閉塞，高度狭窄や脳循環 の評価はされておらず，術後収縮期血圧 $90 \mathrm{mmHg}$ 以下の 血圧低下と脳梗塞発症の関連性の検討としては不十分であ る.

脳循環に血圧とともに影響を与える $\mathrm{PaCO}_{2}$ については 今回の検討では 1 例を除いては $26 \mathrm{mmHg}$ 以上に維持され ていた。低 $\mathrm{CO}_{2}$ 血症については $\mathrm{PaCO}_{2}$ を $20 \mathrm{mmHg}$ 以下 にすると脳血流量が正常神経機能を営む間值量の 20 $\mathrm{ml} / 100 \mathrm{~g} / \mathrm{min}$ まで低下するといわれており, $\mathrm{PaCO}_{2}$ を 25 $\mathrm{mmHg}$ 以下にしないことが推奨されている ${ }^{4)}$. したがっ て遷延する低血圧および低 $\mathrm{CO}_{2}$ 血症を防ぐことは周術期 合併症を予防するうえで重要であるが，本シリーズの症例 のように $\mathrm{PaCO}_{2}$ を適切に保てば問題がないといえる.

しかし，本シリーズでは術前の MRAにて脳主幹動脈の 閉塞, 高度狭窄を呈した症例はなく, 血管病変としては比 較的軽症例が多かった。一方, Blacker らの報告 ${ }^{1)}$ では椎 骨脳底動脈に狭窄病変のある患者に打ける全身麻酔下手術 後の 50 例中 3 例 (6\%) に脳梗塞の発症を認めているが， 1 例は股関節置換術で術中収縮期血圧が $80 \mathrm{mmHg}$ の状態が 40 分持続しており，他の 2 例は冠動脈バイパスの手術で あった。したがって本シリーズでは脳主幹動脈の閉塞, 高 度狭窄症が検討症例に含まれていないので脳主幹動脈の閉 塞，高度狭窄がある症例では全身麻酔の脳への影響を議論
できない.しかし，本シリーズのように脳主幹動脈に閉塞， 高度狭窄を呈していない軽症の症例では，高齢で脳血管障 害が存在しても適切な麻酔を行えば全身麻酔が脳に影響を 与えないといえる.

\section{結語}

全身麻酔が高齢者虚血性脳血管障害既往の脳に影響する かを明らかにするため，軽症の虚血性脳血管障害既往のあ る 70 歳以上の高齢者における脳神経外科，心臟外科手術 を除く全身麻酔下手術の周術期虚血性脳血管障害合併症に ついて検討を行った。

未破裂脳動脈瘤の手術において, 高齢で虚血性脳血管障 害の既往がある患者に対し，術後虚血性脳血管障害が生じ た場合に手術そのものによる合併症ではなく，全身麻酔を その誘因のひとつとしていることがある. しかし，今回の 検討から，症例数を重ねる必要があると思われるが，高齢 者で虚血性脳血管障害の既往ある患者においても脳主幹動 脈に閉塞，高度狭窄を呈していないリスクの低い症例で は，適切な麻酔を行えば全身麻酔が脳に影響を与えないと 考える。

\section{文献}

1) Blacker D, Flemming K, Wijdicks E: Risk of ischemic stroke in patients with symptomatic vertebrobasilar stenosis undergoing surgical procedures. Stroke 24: 2659-2663, 2003

2）糟谷英俊, 恩田英明, 竹下幹彦, ほか：未破裂脳動脈瘤の 治療指針．脳卒中の外科 29: 282-285, 2001

3) Landercasper J, Merz B, Cogbill T, et al: Perioperative stroke risk in 173 consecutive patients with a past history of stroke. Arch Surg 125: 986-989, 1990

4) Lassen NA: blood flow of brain and spinal cord, in Cottrell JE, Turndorf H (eds): Anesthesia and Neurosurgery. St Louis, The CV Mosby, 1986, pp1-21

5) Limburg M, Wijdicks EF, Li H: Ischemic stroke after surgical procedures: clinical features, neuroimaging, and risk factors. Neurology 50: 895-901, 1998

6）松本勝美, 赤木功人, 安部倉信, ほか：脳虚血病変精査中 に発見された未破裂脳動脈瘤の治療選択と合併症．脳神経 外科 28: 699-703, 2000

7）永島雅文，根本正史，波出石弘，ほか：虚血性脳血管障害 を合併した未破裂脳動脈瘤の外科治療。脳卒中の外科 16 : 219-223, 1988

8) Parikh S, Cohen JR: Perioperative stroke after general surgical procedures. N Y State J Med 93: 162-165, 1993

9) Wirth FP, Laws ER, Piepgras D, et al: Surgical treatment of incidental intracranial aneurysms. Neurosurgery 12: 507-511, 1983 